\title{
SIGNA
}

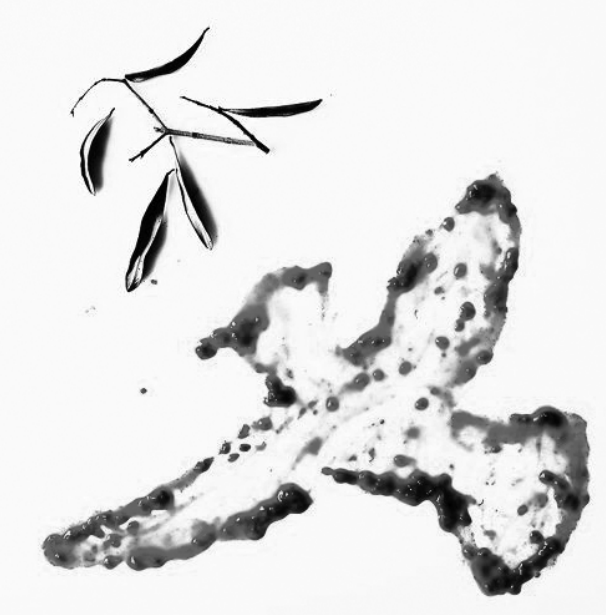

REVISTA DE LA ASOCIACIÓN ESPAÑOLA DE SEMIÓTICA

2011

20

CENTRO DE INVESTIGACIÓN DE SEMIÓTICA LITERARIA, TEATRAL Y NUEVAS TECNOLOGÍAS.

ISSN 1133-3634

UחED Editorial

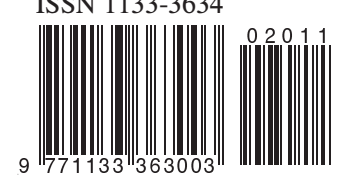

DEPARTAMENTOS DE LITERATURA ESPANOLA Y TEORÍA DE LA LITERATURA Y FILOLOGÍA FRANCESA

UNED 


\section{LA ERA DEL DRAMA EN TELEVISIÓN. PERDIDOS, CSI: LAS VEGAS, EL ALA OESTE DE LA CASA BLANCA, MUJERES DESESPERADAS Y HOUSE}

\section{Anna TOUS ROVIROSA}

(Barcelona: Editorial UOCpress, 2010)

El libro de Anna Tous Rovirosa, La era del drama en televisión, dedicado a las series americanas Perdidos, CSI: Las Vegas, El ala oeste de la Casa Blanca, Mujeres desesperadas y House, es el más completo y rico que sobre el tema se ha publicado en español. Estos productos, que develan y apasionan a espectadores de todo el mundo (entre los que me incluyo), merecían un examen como éste.

El enfoque de Anna Tous, del cual en su prólogo Roman Gubern dice que es «ecléctico», «multipolar», opera en distintos niveles. Y se muestra rico y más explicativo, en nuestra opinión, que ciertos análisis cuantitativos que de estos productos se han realizado. Por mi parte, quisiera destacar, en la medida en que es posible en un espacio breve como el de la reseña, dos importantes operaciones.

En sincronía, parte de la identificación de estos productos como pertenecientes al macrogénero drama. Pero enseguida Anna Tous sofistica ese análisis y propone cómo trabaja, en cada caso, una hibridación específica gé- 
neros. Así, destaca, por ejemplo, que en Perdidos domina un pastiche multigénero (aventuras, lo sobrenatural, la tele-realidad, etc.); que en CSI: Las Vegas lo que domina es el policial, pero desarrollado en el subgénero «forense»; que en Mujeres desesperadas reina una comedia negra femenina de tonalidad agridulce y que en House la hibridación articula tradiciones como las series hospitalarias y las policíacas. El macrogénero drama, de este modo, funciona como un gran envoltorio en el que sofisticados procedimientos de hibridación le dan a cada producto su diferente identidad.

Además, Tous pone enseguida la lupa en las operaciones. Y aquellas en las que pone acento no son menores, porque caracterizan en alguna medida no sólo a estas «series de calidad», que son sus objetos de estudio, sino, también, podría decirse, al cine americano actual (luego de la era clásica, estudiada por Christian Metz) y, por consiguiente, a gran parte de la narrativa ficcional audiovisual que desde Estados Unidos hoy se nos ofrece (por otros caminos, en cambio, parece desarrollarse el cine europeo, en especial el francés, que tiene en Cannes una vidriera que nos permite interpretar cuáles son sus tendencias valoradas: narraciones más respetuosas a la hora de contar «historias de vida» - La cinta blanca, Entre los muros, El viento que acaricia el prado - menos variación sistemática ficcional de mundos diegéticos, menos alteración sistemática de la cronología, etc.).

¿A qué nos referimos cuando señalamos que pone la lupa en distintas operaciones? Por ejemplo, al uso sistemático de operaciones de la anacronía que muchas de estas series llevan a cabo y que Anna Tous focaliza, que nos revelan un aspecto clave de las máquinas ficcionales actuales: las recurrentes analepsis (flash-backs y raccontos) que caracterizan a CSI: Las Vegas y a Perdidos y, por sobre todo, a las prolepsis (flash-forward) que combinadas con otras operaciones temporales series como Perdidos despliegan (que nos hablan de una era en que la televisión se muestra madura, en pleno manejo de los recursos narrativos que sus ancestros, el cine y la novela, supieron conquistar). Un cambio que no es sólo narrativo o que afecta únicamente a las estructuras del relato, sino que tiene, también, profundas consecuencias enunciativas.

En diacronía, el trabajo de Anna Tous sorprende por su focalización en las etapas de la historia de la televisión (que no fueron pensadas para los productos ficcionales especialmente, sino para la programación en su conjunto). $\mathrm{El}$ aprovechamiento que realiza de distinciones como que la Paleo TV era didáctica y que poseía un contrato basado en la idea de la cultura popular (evidente a partir de su observación de series como CSI: Las Vegas) a dife- 
rencia del que se impone en la Neo TV, más vinculado al contacto y al entretenimiento, es muy productivo. Porque pone adelante aspectos que en los análisis sobre estos seriales de ficción habitualmente son poco destacados. Y porque incluye a estas series en una historia a la que también pertenecen, que no es otra que la generalmente despreciada de la televisión (un párrafo sobre la Metatelevisión, que no puedo evitar porque es un término que he utilizado para dar cuenta de cierto «giro» de la televisión argentina: Anna Tous ha expandido su uso, que en particular yo había destinado a ciertos productos que trabajan sobre toda la programación, creo que de forma muy productiva).

Por estas razones y muchas más, a las que aquí no puedo hacer referencia, entiendo que el libro Anna Tous es imprescindible para comprender y pensar los avatares de la narrativa ficcional «audiovisual» actual. Una narrativa que, como muestra muy bien en su exposición, ha alcanzado no sólo su madurez, sino también, a su manera, una verdadera cima.

Mario Carlón 